\title{
Contextualism, Subject-Sensitive Invariantism, and the Interaction of 'Knowledge'-Ascriptions with Modal and Temporal Operators*
}

\author{
Michael Blome-Tillmann \\ University College, Oxford
}

\begin{abstract}
Jason Stanley has argued recently that Epistemic Contextualism (EC) and Subject-Sensitive Invariantism (SSI) are explanatorily on a par with regard to certain data arising from modal and temporal embeddings of 'knowledge'-ascriptions. This paper argues against Stanley that EC has a clear advantage over SSI in the discussed field and introduces a new type of linguistic datum strongly suggesting the falsity of SSI.
\end{abstract}

Keywords: Knowledge, Epistemic Contextualism, Subject-Sensitive Invariantism

\section{Introduction}

Ever since Subject-Sensitive Invariantism (SSI) has entered the epistemological scene, a vigorous discussion has evolved as to whether it is superior to one of its main rivals, Epistemic Contextualism (EC). The participants in this discussion have presented a variety of arguments utilising issues concerning topics as diverse as scepticism, closure, the lottery paradox and the normativity of assertion, but have also focused on more linguistic issues such as the felicitousness of certain 'knowledge'-ascriptions and the syntactic properties of the predicate 'know'. ${ }^{1}$ This paper argues that one topic is to be added to this list of issues that can help making an informed decision between EC and SSI, viz. the topic of modal and temporal embeddings of knowledge-ascriptions.

Even though the discussion of such embeddings has been initiated by Stanley (2005) the topic hasn't received much further attention in the literature yet, which is perhaps due to the fact that Stanley makes a fairly convincing case for the view that EC and SSI are explanatorily on a par with regard to the relevant data. ${ }^{2}$ To be more precise, Stanley

* Forthcoming in Philosophy and Phenomenological Research. I am indebted to Dorothy Edgington, John Hawthorne, Jason Stanley, Timothy Williamson, the audience at the Ockham Society in Oxford and an anonymous referee of PPR for helpful comments on earlier versions of this paper.

1 See Hawthorne (2004), Stanley (2005) and Blome-Tillmann (forthcoming).

2 See also Hawthorne (2004, p. 177, fn. 40). 
argues for the view that both theories, EC and SSI, can account for the data concerning temporal embeddings, while both struggle with the data generated by modal ones. Stanley's view can accordingly be depicted by means of the following scorecard, where the ticks symbolise compatibility and the crosses incompatibility with the data in question:

Table I. Stanley's Scorecard

\begin{tabular}{ccc}
\hline & $\begin{array}{c}\text { temporal } \\
\text { embeddings }\end{array}$ & $\begin{array}{c}\text { modal } \\
\text { embeddings }\end{array}$ \\
\hline EC & $\sqrt{ }$ & $\times$ \\
SSI & $\sqrt{ }$ & $\times$ \\
\hline
\end{tabular}

In this paper I call into question the view that EC ties with SSI concerning modal and temporal embeddings. To my mind, the contextualist has, in the discussed field, a clear advantage over the subjectsensitive invariantist, which will become particularly obvious once we consider a new type of linguistic datum, viz. what I call "conjunctive 'knowledge'-ascriptions". Conjunctive 'knowledge'-ascriptions, the paper argues, generate data that do not only conflict with SSI but are rather also suited to shed light on why SSI is troubled by modal and temporal embeddings. Summing up my agenda, the scorecard envisaged in this paper is the following:

Table II. Envisaged Scorecard

\begin{tabular}{cccc}
\hline & $\begin{array}{c}\text { temporal } \\
\text { embeddings }\end{array}$ & $\begin{array}{c}\text { modal } \\
\text { embeddings }\end{array}$ & $\begin{array}{c}\text { conjunctive } \\
\text { ascriptions }\end{array}$ \\
\hline EC & $\sqrt{ }$ & $\sqrt{ }$ & $\sqrt{ }$ \\
SSI & $\times$ & $\times$ & $\times$ \\
\hline
\end{tabular}

Once a case has been made for the view depicted by my alternative scorecard, we have fresh reasons to doubt the accuracy of SSI more generally, i.e. we have fresh reasons to doubt the accuracy of the view that knowledge is sensitive to the subject's context as it has most 
prominently been defended by John Hawthorne and Jason Stanley in the recent literature. ${ }^{3}$

\section{EC and SSI}

What is EC? Informally speaking, EC is the view that there are both contexts in which it is difficult to satisfy the predicate 'know' and contexts in which it is considerably easier to do so. In other words, EC is the view that there are contexts with low standards for the satisfaction of 'know' and contexts with high standards for the satisfaction of 'know', the relevant epistemic standards being determined by the practical goals, interests and presuppositions of the conversational participants. To illustrate this view, epistemic contextualists typically compare 'know' with gradable adjectives such as 'tall' or 'flat': just as who counts as 'tall' in one context of ascription doesn't necessarily do so in another, who counts as 'knowing $p$ ' in one context of ascription doesn't necessarily do so in another. EC is thus a semantic or, as is often said, a linguistic view, viz. the view that 'know' is an indexical expression: 'know' may change its content with context.

To see how this conception of EC as a purely linguistic view can be cashed out in more philosophical detail it is worthwhile taking a brief look at David Lewis's contextualist account of 'knowledge'. Lewis defines the satisfaction of 'knows' as follows:

(L) $x$ satisfies 'knows $p$ ' in $C \leftrightarrow x$ 's evidence eliminates all $\neg p$-worlds, except for those that are properly ignored in $C .{ }^{4}$

In addition to this definition Lewis stipulates a set of rules specifying which possibilities are properly ignored in a given context $C$. It is this set of rules that is meant to determine how the content of 'know' is influenced by particular conversational factors of the ascriber's context.

Leaving aside EC for the moment, let us consider SSI, one of the key rival theories to EC in the literature. As defined by its main advocates, Hawthorne (2004) and Stanley (2005), SSI claims that whether a subject $x$ knows $p$ partly depends on the epistemic standards prevalent in the subject's context. Thus, if Hannah is in a context with low epistemic standards, then Hannah's low epistemic standards determine

${ }^{3}$ See Hawthorne (2004) and Stanley (2005).

${ }^{4}$ Cp. Lewis (1996). In his paper Lewis doesn't ascend semantically and so the impression arises that he defines knowledge rather than the satisfaction of 'knows' in a given context $C$. Since Lewis is a contextualist, however, he is clearly interested in the latter and also makes this clear towards the end of his paper when admitting that he should have ascended semantically, had he wanted to be formally adequate. 
whether she knows $p$. If, on the other hand, Hannah is in a context with high epistemic standards, then Hannah's high epistemic standards determine whether she knows $p$, the epistemic standards of potential third-person ascribers of 'knowledge' being irrelevant with regard to the question of whether Hannah knows.

In one respect SSI is thus very much akin to more traditional epistemological theories: qua invariantism SSI denies that 'know' can change its content with context and thus entails the negation of EC. What distinguishes SSI from more traditional epistemologies, however, is the claim that whether the knowledge-relation obtains in a given case depends partly on the subject's practical interests, goals and presuppositions. ${ }^{5}$ It is due to this claim that SSI is primarily a metaphysical and not a linguistic view: SSI is, after all, a view about the nature of the knowledge-relation and is thus linguistic only insofar as it entails the negation of EC.

To further illustrate the differences between EC and SSI it is instructive to fill in the philosophical details left open by the above characterisation of SSI along similar lines as Lewis did for EC. Lewis's definition (L) can fairly easily be turned into an SSI-account of knowledge, viz. by replacing the phrase 'in $C$ ' in $(\mathrm{L})$, which establishes reference to the ascriber's context, with the phrase 'in $x$ 's context', which establishes reference to the subject's context. Here is $\left(\mathrm{L}^{*}\right)$ :

$\left(\mathrm{L}^{*}\right) x$ satisfies 'knows $p$ ' in $C \leftrightarrow x$ 's evidence eliminates all $\neg p$-worlds, except for those that are properly ignored in $x$ 's context.

If $\left(\mathrm{L}^{*}\right)$ is complemented with Lewis's rules of proper ignoring, we attain a prima facie functional version of SSI. ${ }^{6}$

One further question remains to be addressed at this point: which contextual features do contextualists and subject-sensitive invariantists take to determine epistemic standards? In other words, which contextual features determine that a particular world is or isn't properly ignored in a given context? Of course, each theorist approaches this question in a slightly different manner, but I think it's fair to claim that all theorists, whether contextualists or subject-sensitive invariantists, agree that the epistemic standards in force in a given context $C$ are partly determined by the practical interests of the speakers in $C$. The following versions of DeRose's famous bank case as found in Stanley (2005) illustrate this nicely: ${ }^{7}$

\footnotetext{
5 Stanley dubs his version of SSI 'Interest-Relative Invariantism', but these details are irrelevant here.

6 Note that neither Hawthorne nor Stanley explicate SSI along these lines.

7 See DeRose (1992, p. 913) and Stanley (2005, p. 3-4).
} 
Low Stakes:

Hannah and her wife Sarah are driving home on a Friday afternoon. They plan to stop at the bank on the way home to deposit their pay-checks. It is not important that they do so, as they have no impending bills. But as they drive past the bank, they notice that the lines inside are very long, as they often are on Friday afternoons. Realizing that it isn't very important that their paychecks are deposited right away, Hannah says, 'I know the bank will be open tomorrow, since I was there just two weeks ago on Saturday morning. So we can deposit our paychecks tomorrow morning.'

High Stakes:

Hannah and her wife Sarah are driving home on a Friday afternoon. They plan to stop at the bank on the way home to deposit their pay-checks. Since they have an impending bill coming due, and very little in their account, it is very important that they deposit their paychecks by Saturday. Hannah notes that she was at the bank two weeks before on a Saturday morning, and it was open. But, as Sarah points out, banks do change their hours. Hannah says, 'I guess you're right. I don't know that the bank will be open tomorrow.'

Our intuitions concerning Low Stakes are that Hannah speaks truly when she self-ascribes 'knowledge'. In High Stakes, however, our intuitions are reversed: in High Stakes our intuitions are that Hannah speaks truly when denying that she 'knows that the bank will be open on Saturday' (henceforth 'knows $O$ ').

Now, since Hannah is both subject and ascriber in the above cases, (L)-based EC and ( $\left.\mathrm{L}^{*}\right)$-based SSI can account for our intuitions along the same lines, viz. by claiming that there are uneliminated $\neg O$-worlds that Hannah can properly ignore in Low Stakes but not in High Stakes, the relevant $\neg O$-worlds being $\neg O$-worlds in which the bank has changed its hours recently. The reason why Hannah can properly ignore these $\neg O$-worlds in Low Stakes but not in High Stakes has, of course, to do with the fact that the stakes for Hannah are low in Low Stakes but high in High Stakes. Thus, EC and SSI agree that the stakes in a given context $C$ or, in other words, the speakers' practical interests in $C$ can more or less directly determine the epistemic standards in force in $C .{ }^{8}$

\footnotetext{
8 Jonathan Schaffer (2006) calls into question the view that a difference in Hannah's practical interests explains the difference in our intuitions in these cases. According to Schaffer, the mentioning of the alternative possibility accounts for this difference.
} 


\section{Modal Embeddings}

We now have the necessary background to discuss Stanley's arguments concerning modal and temporal embeddings. Let us firstly take a look at the case of modal embeddings. Consider Low-Stakes again: in the imagined situation nothing much is at stake, and since Hannah has been at the bank on a Saturday two weeks earlier, Hannah speaks truly when she claims 'I know $O$ '. Now suppose that right after uttering 'I know $O$ ' Hannah adds the following counterfactual:

(1) But if I had a bill coming due, then I wouldn't know $O{ }^{9}$

As Stanley admits, our intuitions are here that Hannah's assertion of (1) expresses a falsehood: Hannah knows $O$, and even if she had a bill coming due, she would still do so. SSI is thus incompatible with our intuitions, for it entails that Hannah's assertion of (1) expresses a truth: according to SSI, the counterfactual situation described in the antecedent of (1) is a high-stakes situation, such that merely having been to the bank on a previous Saturday doesn't suffice for Hannah to know $O$. Thus, SSI entails that (1) expresses a truth, and this is surely implausible.

Now, Stanley's strategy concerning modal embeddings such as (1) is simply to bite the bullet. However, Stanley attempts to play down the problem by arguing that other epistemological theories entail the truth of statements very similar to (1). The two candidates Stanley mentions are reliabilism and, of course, EC. Let us firstly consider Stanley's remarks on reliabilism.

To show that reliabilism has implausible consequences concerning modal embeddings, Stanley considers a version of Ginet's fake-barn example. As Stanley sets up the example, Bill is driving through fakebarn country, in which there are as many fake barns around as there are real barns. By chance, Bill is standing in front of a real barn and believes that he does. Since perception, however, is not a reliable method of belief-formation in fake-barn country, Bill doesn't know that he is standing in front of a real barn. Now, imagine somebody asserts (2):

(2) "Poor Bill. He doesn't know that is a barn. But if there were fewer fake barns around then he would know that is a barn." 10

Stanley is clearly right in assuming that (2) as asserted in the imagined situation expresses a falsehood. On the basis of this observation, however, Stanley then goes on to argue that since "we do not take the

\footnotetext{
9 Cp. Stanley (2005, p. 106).

10 Ibid., p. 114.
} 
fact that reliabilism entails the truth of $[(2)]$ to show that reliabilism is false $[\ldots]$, it would be excessively hasty to take counterfactuals such as $[(1)]$ as demonstrating the falsity of [SSI]."11

Now, the problem with this line of reasoning is, I take it, that reliabilism doesn't entail (2). To see this let us take a closer look at the quantifier 'fewer' in (2): exactly how many fewer fake barns are necessary for Bill to know that he is looking at a barn? Of course, this question doesn't have an answer or we are, at least, not in a position to know the answer, depending on one's favourite account of vagueness. However, the crucial point here is that one fake barn fewer is fewer fake barns already. Thus, (2) claims that Bill would know that he is looking at a barn in a world in which there is only one fake barn fewer than there actually are. This is surely false, however, for in the considered world Bill's belief would still be true as a matter of pure luck only, and no sane reliabilist would want to claim the contrary. Thus, (2) is not entailed by reliabilism.

Here is a counterfactual that is entailed by reliabilism:

$\left(2^{*}\right)$ Poor Bill. He doesn't know that is a barn. But if there were no (or almost no) fake barns around then he would know that is a barn.

I have very strong intuitions that $\left(2^{*}\right)$ is true. However, leaving $\left(2^{*}\right)$ aside, note that Stanley hasn't succeeded in showing that reliabilism entails the truth of counterfactuals as implausible as (1) or (2). Let us now turn to Stanley's arguments for the view that EC does.

To illustrate the view that EC entails the truth of statements such as (1) Stanley takes Lewis's account as an example. To be precise, Stanley claims that if we model the context-sensitivity of 'know' along the lines of (L), then EC entails the truth of (3) as uttered in High-Stakes:

(3) "Hannah doesn't know that the bank will be open on Saturday. But if I [were to properly ignore] that she has a bill coming due, she would know that the bank will be open on Saturday." ${ }^{2}$

Now, the intuitive contextualist reply to this objection is that the counterfactually embedded 'know' in (3) takes the same semantic value as the unembedded 'know' in (3): both is assigned a semantic value in the context of utterance, not in the counterfactual situation talked about in the antecedent of (3); therefore, (3) expresses a falsehood. However, Stanley thinks that if (L)-based EC were true, then the counterfactually embedded occurrence of 'know' in (3) should take its semantic value in the relevant counterfactual situation, and he backs up this claim by

\footnotetext{
11 Ibid.

12 Ibid., p. 110.
} 
comparing 'know' to quantified noun phrases such as 'every bottle'. Here is Stanley's example:

Strange Habits:

"John has the strange habit of buying exactly 70 bottles every time he goes to a supermarket. Suppose that John visits a supermarket that has exactly 70 bottles on the shelf, and purchases every bottle. Someone could then truly utter the sentence:

(4) If there were a few more bottles on the shelf, John would not have purchased every bottle." 13

Note that 'every bottle' in (4) takes its semantic value in the counterfactual situation in which there are more than 70 bottles on the shelf - otherwise (4) couldn't express a truth. Now, here is Stanley's point: since 'every bottle' in (4) takes its value in the counterfactual situation, so should 'know' in (3), assuming that the semantics of 'know' is to be modelled along Lewis's lines, i.e. on the basis of the contextsensitivity of the quantified noun phrase 'every $\neg p$-world that...' Thus, according to Stanley, (3) as uttered in High-Stakes should express a truth, and this is surely a rather unpleasant result for the Lewisian contextualist. ${ }^{14}$

However persuasive this line of reasoning against (L)-based EC may be, note in reply to Stanley that his argument rests on a very strong assumption about the semantics of counterfactually embedded quantified noun phrases, viz. the following principle:

(ST) Counterfactually embedded quantified noun phrases take their semantic values in the relevant counterfactual situation described in the antecedent of the counterfactual.

Considering Strange Habits, (ST) has some initial plausibility: clearly, 'every bottle' in (4) receives its semantic value in the counterfactual situation in which there are more than 70 bottles on the shelf. However, note that (ST) is supported by Strange Habits only, so if we can find examples of counterfactually embedded quantified noun phrases that are assigned semantic values in the context of utterance rather than in the relevant counterfactual situation, then (ST) - and with it Stanley's argument against EC-must fail. Here are a few examples of this sort:

\footnotetext{
13 Ibid., p. 109.

14 Stanley formulates this objection differently, claiming, for instance, that 'every' is assigned a property that changes its extension with the circumstances of evaluation, rather than a set as a simple domain. I leave aside the unnecessary technical detail in my discussion.
} 
(5) If there were no philosophers, then the philosophers doing research in the field of applied ethics would be missed most painfully by the public.

(6) If there were no beer, everybody drinking beer on a regular basis would be much healthier.

(7) If I suddenly were the only person alive, I would miss the Frege scholars most.

These counterfactual conditionals are obviously felicitous and, possibly, even true. However, the only sensible readings available for these counterfactuals are readings on which the embedded quantified noun phrases receive their semantic values in the context of utterance rather than in the relevant counterfactual situation. Thus, (5)-(7) are rather clear counterexamples to (ST).

Another interesting example strengthening my argument against (ST) is the following:

(8) If John Hawthorne were a professor of biochemistry, his students would know the difference between lactose and sucrose.

Interestingly, (8) is ambiguous between two readings: one according to which, in the counterfactual situation, John's counterfactual biochemistry students know the difference between lactose and sucrose, and one according to which, in the counterfactual situation, John's actual philosophy students know that difference. Due to charity, the default interpretation in this case is surely the former reading: there are simply no reasons why John's actual students should have the mentioned piece of knowledge in the counterfactual situation. However this may be, note that, according to (ST), there shouldn't be any ambiguity here: (ST) forces us to the view that the only possible interpretation of (8) is the first one, but this is surely not the case.

Another point I would like to emphasise here is that we are usually free to rigidify quantified noun phrases by means of the 'actually'operator. The second reading of (8), for instance, can be made explicit by disambiguating as follows:

(9) If John Hawthorne were a professor of biochemistry, his actual students would know the difference between lactose and sucrose.

As I have mentioned already, (9) is probably false. However, the important point here is that by means of the 'actually'-operator quantified noun phrases can be rigidified relative to the context of utterance. One might thus suggest that to formally avoid Stanley's objection, one 
could simply rigidify the quantified noun phrase 'all $\neg p$-worlds that...' in (L) by means of the 'actually'-operator. However, note that such rigidification isn't necessary, for my presentation of Lewis's views in this paper specified right from the start that 'know' must take its semantic value in the context of utterance. Reconsider my earlier paraphrase of Lewis's analysis:

(L) $x$ satisfies 'knows $p$ ' in $C \leftrightarrow x$ 's evidence eliminates all $\neg p$-worlds, except for those that are properly ignored in $C$.

From a contextualist point of view, the important bit in (L) is, of course, the phrase 'in $C$ '. However, note that the 'in $C$ ' in (L) also ensures that problems concerning modal embeddings cannot arise for (L)-based EC: it is made explicit in the very analysis of the satisfaction of 'know' that the $\neg p$-worlds to be eliminated in a given context of utterance $C$ are those that aren't properly ignored in that given context of utterance $C .{ }^{15}$ The semantics of 'know' as explicated in (L) thus doesn't allow for counterfactually embedded occurrences of 'know' to take their semantic values in the relevant counterfactual situation. Formulating Lewis's views meta-linguistically therefore precludes Stanley's objection right from the start, and SSI in general is, eventually, the only epistemological theory that is troubled by modal embeddings.

\section{Temporal Embeddings}

Let us now turn to Stanley's considerations about temporal embeddings. From the above discussion it is obvious that a similar problem as the one concerning modal embeddings arises concerning temporal embeddings as well: Hannah's practical situation can, after all, not only vary from world to world but also from time to time. To see this in detail suppose that Hannah is, on Thursday, in a high-stakes context: she has a bill coming due on Monday and, accordingly, doesn't know $O$ on Thursday. Imagine further that one day later, on Friday, the company to whom the bill was owed decided to alleviate the debt of all of its customers. Then, on Friday, Hannah is in a low-stakes situation and therefore knows $O$ on Friday. As a consequence, SSI implausibly entails that Hannah speaks truly if, on Saturday, she asserts:

(10) I didn't know $O$ on Thursday, but on Friday I did. ${ }^{16}$

\footnotetext{
15 ' $C$ ' is a rigid designator.

16 The example is Stanley's. See Stanley (2005, p. 106).
} 
Why doesn't (10) seem true? Obviously, it doesn't seem true because Hannah's evidence, beliefs and the relations between these two were exactly the same on Thursday and Friday. If these were exactly the same, however, then what accounts for the alleged difference in Hannah's epistemic states contended by (10)? According to SSI, this difference is due to a difference in Hannah's practical interests. However, the crucial point here is the implausibility of the view that a difference in practical interests can bring about a difference in epistemic states: we have clear intuitions that (10) expresses a falsehood, and this suggests that Hannah's practical interests are, after all, epistemologically irrelevant. How can the defender of SSI avoid this rather unpleasant consequence?

Firstly, the defender of SSI may dispute that SSI entails the truth of the second conjunct of (10): Hannah didn't know $O$ on Friday. To illustrate how one might argue for this view, note that SSI is merely the view that the subject's practical interests are relevant to knowledge. But there is no implication that salience is not relevant: in fact, Hawthorne (2004) expresses sympathy with the view that it is when he claims that "[i]f $S$ thinks that $p$, but a certain counterpossibility is salient to $S$, then $S$ does not know that $p . " 17$ Therefore, even if Hannah's practical interests change on Friday -if she enters a low-stakes context on Friday - it doesn't follow that she automatically comes to know $O$ on Friday. For, in remembering her recent high-stakes context, that context may still be salient on Friday and so might infect her Friday-context. ${ }^{18}$

But how plausible is the view that Hannah's low-stakes Fridaycontext is inevitably infected by her high-stakes Thursday-context? Consider the following case:

Afternoon Low Stakes:

It is Friday morning, and Hannah and her wife Sarah receive a letter informing them that a company to whom they owed an important bill has alleviated the debt of all of its customers. Hannah and Sarah are pleased: the sum they owed was significant. In the afternoon, on their way home from work, Hannah and Sarah plan to stop at the bank to deposit their paycheques. It is not important that they do so, as they now have no impending bills. But as they drive past the bank, they notice that the lines inside are very long, as they often are on Friday afternoons. Realizing that it isn't very important that their paychecks are deposited right away, Hannah says, 'I

\footnotetext{
17 Hawthorne (2004, p. 159) assumes that $S$ cannot eliminate the counterpossibility at issue.

${ }^{18} \mathrm{I}$ am indebted to an anonymous referee of this journal for this point.
} 
know the bank will be open tomorrow, since I was there just two weeks ago on Saturday morning. So we can deposit our paycheques tomorrow morning.'

What is crucial about Afternoon Low Stakes is, of course, not only that the stakes are low on Friday afternoon but also that, on Friday afternoon, Hannah and Sarah pay no attention whatsoever to the possibility that the bank has changed its hours recently. Thus, the possibility that the bank has changed its hours recently is not salient on Friday afternoon and Hannah's low-stakes Friday-context is not infected by her high-stakes Thursday context: Hannah speaks truly when asserting 'I know $O$ ' on Friday afternoon. If Hannah knew $O$ on Friday afternoon, however, and didn't know $O$ on Thursday, because Thursday was a high-stakes situation, then it follows that, on Saturday, Hannah speaks truly when asserting (10). ${ }^{19}$

Let us leave behind the idea that SSI entails the falsity of the second conjunct of (10) and consider Stanley's remarks on the issue of temporal embeddings. How does Stanley intend to avoid the problem generated by (10)? Here is Stanley:

"[W]hether [SSI] entails the truth of $[(10)]$ depends upon what one takes to be the correct temporal metaphysics. For example, if one thinks that there are future facts, then it is a fact on Thursday that the company will alleviate the debt of all of its customers. If so, then perhaps Thursday is not a High Stakes situation for Hannah after all. Since whether [SSI] has unintuitive consequences in the temporal case depends upon debatable metaphysical issues, I will focus on [SSI]'s unintuitive modal consequences in what follows." 20

Even though realism about future facts may be a debatable position in metaphysics, let us grant Stanley that on Thursday it was a fact that on Friday the company would alleviate the debt of all of its customers. Now, even if we allow Stanley this debatable view it is still not clear

\footnotetext{
19 It might be objected here that, on Saturday, Hannah doesn't know $O$ because, on Saturday, she remembers Thursday's high-stakes situation and therefore attends to the possibility that the bank has changed its hours, which then renders that possibility salient. If Hannah doesn't know $O$ on Saturday, however, then she cannot felicitously assert (10) on Saturday: (10) entails $O$ (factivity) and Hannah therefore violates, in asserting (10) on Saturday, the Knowledge Rule of Assertion ('Assert $p$ only if you know p'; see Williamson (2000, ch. 11)). The defender of SSI might thus aim to give a pragmatic explanation of the infelicity of Hannah's assertion of (10) on Saturday. Such a move, however, can be blocked rather easily, viz. by ensuring that Hannah knows $O$ on Saturday; for instance, by letting her assert (10) while queuing in the bank.

20 Ibid., p. 107.
} 
why he thinks that it follows that Thursday was a low-stakes situation for Hannah.

To illustrate why this doesn't follow, consider a case in which, on Thursday, Hannah has a firm and well-justified belief that she has a bill coming due on Monday, while in fact the company will alleviate her debt on Friday. Assuming realism about future facts, it is, in this case, a fact on Thursday that Hannah doesn't have a bill coming due on Monday. However, since, on Thursday, Hannah has a firm and welljustified belief that she has a bill coming due on Monday, she also has, on Thursday, a firm and well-justified practical interest in whether the bank will be open on Saturday. Thus, Thursday is, after all, a highstakes situation for Hannah and she cannot, on Thursday, properly ignore the possibility that the bank has changed its hours. ${ }^{21}$

The crucial point underlying this line of reasoning is, of course, the assumption that, on Thursday, Hannah's practical interests are determined by her firm and well-justified beliefs about the future rather than by the future itself. That there is, in the case at issue, such a close connection between Hannah's beliefs on the one hand and her practical interests on the other becomes fairly obvious once we take into account that Hannah loses her practical interest in whether the bank will be open on Saturday in the very moment, on Friday, in which she ceases to believe - firmly and justifiably - that she has a bill coming due on Monday. Thus, it is a change in Hannah's beliefs that brings about a change in Hannah's practical interests and thus a change of Hannah's context from high-stakes to low-stakes.

Of course, Stanley may deny my assumption that, on Thursday, Hannah's practical interests are determined by her firm and well-justified beliefs about the future rather than by the future itself. In fact, Stanley seems to think that it is always actual, and not perceived, stakes that matter to what a subject can properly ignore. ${ }^{22}$ Now, even though this view seems, on the background of the above case, rather implausible, it is worthwhile noting that one's firm and well-justified beliefs about what is at stake are in fact sometimes irrelevant with regard to one's practical interests: if a glass contains poison, it is not in Hannah's

\footnotetext{
21 The rule doing the work here is Lewis's Rule of Belief, according to which one cannot properly ignore possibilities that one ought to believe, i.e. propositions that one's evidence confirms. Cp. Lewis (1996, pp. 226-7). Note that Stanley (2005, p. 92) commits himself to a similar principle, when claiming that "[a] proposition is a serious practical question [that cannot be legitimately ignored by] an agent, if there are alternatives to that proposition that the [agent] ought rationally to consider in decision making." Clearly, in the described case Hannah, on Thursday, "ought rationally to consider in her decision making" the possibility that the bank has changed its hours and will therefore be closed on Saturday.

22 See, for instance, Stanley (2005, p. 5).
} 
interest to drink from it, even if she has a firm and well-justified belief that it contains medicine. Thus, Stanley is right to assume that one's practical interests are usually determined by one's actual stakes. However, as my above example has shown, there are also exceptions to this rule, i.e. there are also cases in which the perceived stakes - and not the actual ones - determine one's practical interests. ${ }^{23}$

If this is correct, however, and Hannah's practical interests on Thursday are in fact determined by her firm and well-justified beliefs about the future, then Stanley's argument in defence of SSI collapses: since firm and well-justified beliefs about the future can well be false, the (debatable) reality of future facts is irrelevant with regard to the question of whether Hannah was in a high-stakes context on Thursday. Thus, a realist stance towards future facts doesn't help SSI out of the predicament generated by (10): SSI is still forced to adopt the implausible view that (10) expresses a truth and that is surely a cost to the view.

Before moving on let me briefly illustrate how EC can account for the intuition that (10) expresses a falsehood. The crucial point here is that any particular assertion of (10) is located within a particular context of utterance $C$. According to EC, the epistemic standards of this context $C$ determine the semantic value of both occurrences of 'know' in (10). Thus, the first and the second occurrence of 'know' in (10) inevitably take the same semantic value. ${ }^{24}$ As a consequence, no matter which context we consider, (10) always expresses a falsehood, assuming that Hannah had the same evidence on Thursday and Friday. Concerning temporal embeddings, EC has a clear advantage over SSI.

\section{Conjunctive Ascriptions}

Thus far we have seen that there are good reasons for the view that SSI is the only epistemological theory on the market that is troubled by both modal and temporal embeddings. In this section I would like to draw attention to another type of example that causes trouble for SSI, viz. examples that I call 'conjunctive ascriptions'.

Suppose that John and Paul have exactly the same evidence, while John is in a low-stakes situation towards $p$ and Paul in a high-stakes

\footnotetext{
${ }^{23}$ In which cases do the actual stakes determine one's practical interests and in which cases the perceived ones? I take it that one's practical interests are usually determined by whichever stakes are higher: if one's actual stakes are higher, then one's actual stakes determine one's practical interests, whereas if one's perceived stakes are higher, then one's perceived stakes determine one's practical interests.

${ }^{24}$ No contextual change mid-sentence is triggered by the assertion of (10).
} 
situation towards $p$. Bearing in mind that SSI is the view that whether one knows $p$ depends on one's practical situation, SSI entails that one can truly assert:

(11) John and Paul have exactly the same evidence for $p$, but only John has enough evidence to know $p$, Paul doesn't. ${ }^{25}$

The reason why SSI entails that (11) expresses a truth in the imagined situation is, obviously, that the evidence John and Paul have is sufficient for 'knowing $p$ ' in John's context, but not so in Paul's. Now, I find (11) to be a fairly unpleasant consequence of SSI. However, before drawing conclusions from this datum, we need to consider an objection to my contention that SSI entails the truth of (11).

To avoid problematic examples such as (11), the subject-sensitive invariantist might be tempted to adopt Williamson's claim that one's evidence consists of all and only those propositions that one knows: $\mathrm{E}=\mathrm{K} .{ }^{26}$ Now, once we assume that $\mathrm{E}=\mathrm{K}$ - and both Hawthorne and Stanley seem to be attracted to this view - it follows, assuming SSI, that not only knowledge but also evidence is infected by one's practical interests. ${ }^{27}$ Consequently, if $\mathrm{E}=\mathrm{K}$, then it is not at all clear that John and Paul can have the same evidence, given that the stakes change so radically between their respective situations. Assuming that $\mathrm{E}=\mathrm{K}$, the subject-sensitive invariantist may thus maintain that it is by no means clear that SSI, when paired with the view that $\mathrm{E}=\mathrm{K}$, entails the implausible (11).

Even though this line of reasoning may seem promising initially, I believe that it is eventually not convincing. To see this note that, assuming SSI, John is merely in a position to know more than Paul and thus, assuming that $\mathrm{E}=\mathrm{K}$, he is merely in a position to have more evidence than Paul. It doesn't follow from SSI alone, however, that John has in fact more knowledge and thus has in fact more evidence than Paul, and this is simply so because John may fail to believe - and thus fail to know - all those propositions that he is in a position to know but Paul isn't. Assuming SSI, it is thus very well possible that John and Paul have exactly the same knowledge and therefore also have, assuming that $\mathrm{E}=\mathrm{K}$, exactly the same evidence, even though the

\footnotetext{
${ }^{25}$ I take it that having enough evidence to 'know $p$ ' in $C$ just means having evidence such that one is in a position to 'know $p$ ' in $C$, rather than having evidence such that one 'knows $p$ '. Thus, another way to formulate (11) would be as follows: 'John and Paul have exactly the same evidence for $p$, but only John is in a position to know $p$, Paul isn't.'

26 Thanks to Jason Stanley here. For the view that E=K see Williamson (2000, ch. 9).

27 See Stanley (2005, pp. 88-9) and Hawthorne (2004, p. 139).
} 
stakes differ rather radically between their respective situations. Thus, SSI is committed to the view that there are possible cases in which John and Paul have exactly the same evidence for $p$, while only John is in a position to know $p$ but Paul isn't. In other words, there are, according to SSI, cases in which (11) expresses a truth, even granting that $\mathrm{E}=\mathrm{K} .^{28}$

Now, as I have emphasised above, I find (11) to be a fairly unpleasant consequence of SSI. However, note that conjunctive ascriptions such as (11) are not just another type of construction that turns out problematic for SSI. To the contrary, what is really interesting about conjunctive ascriptions is that they don't contain temporal or modal operators. Thus, concerning (11) the subject-sensitive invariantist cannot attempt to find comfort in her temporal metaphysics or claim extenuating circumstances because modal operators behave funnily in all kinds of situations. Concerning (11), there simply isn't much sophisticated explaining away to be made. Thus, examples such as (11) show with even more clarity what the above-discussed examples containing modal and temporal operators have shown: knowledge is insensitive to the subject's practical situation. ${ }^{29}$

\section{References}

Blome-Tillmann, M. (forthcoming). "The Indexicality of 'Knowledge'." Philosophical Studies.

DeRose, K. (1992). "Contextualism and Knowledge Attributions." Philosophy and Phenomenological Research 52: 913-929.

\footnotetext{
28 Presumably, the only propositions that John is in a position to know but Paul isn't are $p$ and composed propositions containing $p$, such as the disjunction $(p \vee q)$ or the conjunction $(p \wedge q)$, where $q$ is an irrelevant truth that both John and Paul know. Now, given that $\mathrm{E}=\mathrm{K}$ and that John in fact knows $p$ but Paul doesn't, it follows that John has more evidence for $p$ than Paul: $p$ is evidence for itself (cp. Williamson (2000, p. 187)) and it is part of John's evidence, but not of Paul's. Note, however, that even though John has more evidence for $p$, he doesn't have more non-circular evidence for $p$. Thus, the objection that SSI doesn't entail (11) because E=K can also be circumvented by inserting 'non-cricular' into (11).

29 Isn't pointing out to the subject-sensitive invariantist that her view is implausible and counterintuitive akin to pointing out to the sceptic that it's implausible and counterintuitive that we don't know anything? It presumably is. However, note that this doesn't help the defender of SSI: epistemologists object to scepticism precisely on the basis of its implausibility and counterintuitiveness. Moreover, I take it that our intuitive reactions to individual cases such as (1), (10) and (11) are, as Stanley (2005, p. 11) puts it in a different context, "not [just] random noise". Rather, they can plausibly be interpreted as natural reflections of the fact that one's knowledge is not conceptually connected to one's practical interests in the way SSI suggests it is.
} 
Hawthorne, J. (2004), Knowledge and Lotteries, Oxford: OUP.

Lewis, D. (1996), "Elusive Knowledge", Australasian Journal of Philosophy 74: 54967.

Schaffer, J. (2006), "The Irrelevance of the Subject: Against Subject-Sensitive Invariantism", Philosophical Studies 127: 87-107.

Stanley, J. (2005), Knowledge and Practical Interest, Oxford: OUP.

Williamson, T. (2000), Knowledge and Its Limits, Oxford: OUP. 